\title{
EL SECTOR CAFETALERO EN EL PERÚ: EL CASO PERHUSA-CAFÉ ALTOMAYO
}

$\mathrm{N}$ uestra hipótesis de desarrollo para el Perú pasa por el incremento de su competitividad mediante el desarrollo de industrias y empresas que incorporen base tecnológica y privilegien la manufactura basada en recursos no naturales (alta y media tecnología). Considetamos vital en el corto y mediano plazo vigilar y promover el desarrollo de productores agrarios organizados en cadenas productivas como unidades de gestión de recutsos naturales que persigan una agricultura eficaz en términos de sostenibilidad económica, social y ambiental.

La cadena productiva del café constituye una de las más significativas, solo los pequeños productores suman más de 125 mil y conducen un promedio dos hectáreas. Estos productores representan el $90 \%$ de la producción total de café sin asistencia económica ni técnica. Paradójicamente, los campos de cultivo artesanal representan unos costos de producción del café inferiores a los de los campos con cultivo tecnológico, S/.2.540.00 y S/. 8.639.00, tespectivamente (los cultivos tecnológicos añaden el abonamiento, control fitosanitario, fertilizantes y pesticidas), Como podrá apreciarse, estos pequeños agricultores, de manera natural, cultivan orgánicamente. 


\section{El café en el mundo}

En el gráfico $n .{ }^{\circ} 1$ se aprecia que los países desarrollados son los principales importadores y consumidores de café, y estos no son precisamente productores, entre ellos destacan Estados Unidos y Alemania como los principales destinos de las exportaciones de América latina, Asia y África.

\section{Principales países importadores de café}

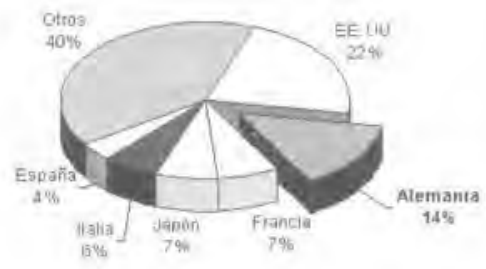

\begin{tabular}{|l|r|}
\hline \multicolumn{1}{|c|}{ Paises } & $\begin{array}{r}\text { Prome dio } 97-01 \\
\text { (sacos de } 80 \mathrm{~kg} \text { ) }\end{array}$ \\
\hline EE UU & 21.891 .994 .40 \\
\hline Alemania & $\mathbf{1 4 . 3 3 8 . 6 7 9 . 8 0}$ \\
\hline Francia & 5.755680 .40 \\
\hline Japón & 6.560 .447 .40 \\
\hline italia & 6.110 .681 .40 \\
\hline Esparia & 3.914 .413 .00 \\
\hline Otros & 39.938 .334 .85 \\
\hline Total anual & 99.510 .231 .25 \\
\hline
\end{tabular}

En el gráfico $n .^{\circ} 2$ se observa que la producción y consumo de café se han incrementado en el ámbito global; sin embargo, la producción (oferta) se ha incrementado mucho más en términos relativos, lo que habtía impactado negativamente en los precios internacionales, lo que generaría grandes pérdidas para los productores ( $8 \%$ por encima de la demanda real). 


\section{Producción y Consumo de Café al nivel global}

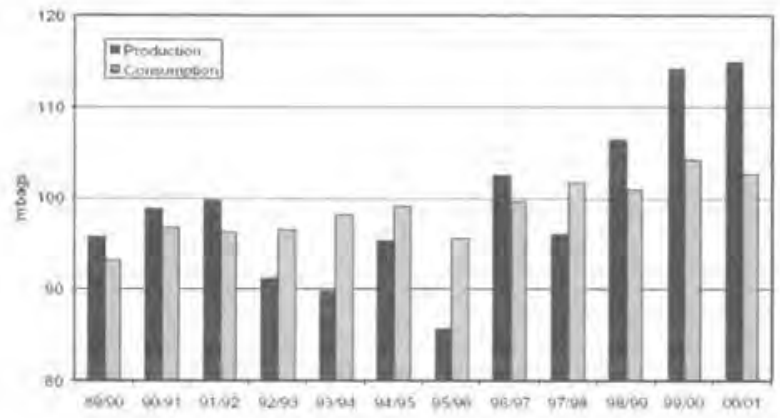

Fuente: Camara Alerrama

\section{Variedades comerciales}

El cafeto pertenece a la familia de las Rubiáceas, al género Coffea, que comprende más de sesenta especies, de las cuales, dos son las más cultivadas:

- Arábiga (Coffea arábica), originaria de Etiopía, es la más conocida, divulgada y apreciada, representan el $70 \%$ de la producción mundial. Las variedades más seleccionadas se cultivan en las zonas altas de América Latina (Colombia, México, Perú), África, Kenya y Etiopía. Es un café muy aromático; su cultivo se realiza en zonas altas. 
- Robusta (Coffea canephora), se presume originaria del África o Indonesia. Según el centro internacional del Café, su demanda se sustenta en las preferencias comerciales de Europa hacia sus ex colonias, su bajo precio, que atrajo nuevos consumidores, las nuevas formas de café, el café soluble y la aparición del proceso de descafeinado, para el que muestra mayores aptitudes, Esta vatiedad se cultiva a nivel del mar y hasta los 600 metros.

Como muestra de las variaciones en el consumo existente por países, en el gráfico n. ${ }^{\circ} 3$ se presentan los consumos en diversos países de la Unión Eutopea, donde la preferencia por la variedad arábiga es marcada, a excepción de Polonia y España.

El consumo del tipo del café varia bastante entre los países de la UE Distribucion Porcentual de las clases de Cafe Verde

\begin{tabular}{|c|c|c|}
\hline Eus & Arabigat & Pueluske \\
\hline Eatgialunemourgo & 42 & de \\
\hline Dinamaroa & 84 & 12 \\
\hline Aigmania & 79 & 21 \\
\hline Fincungie & 89 & 2 \\
\hline Frane is & 00 & $3 A$ \\
\hline Gran Attaña & 80 & 45 \\
\hline tella & 54 & 44 \\
\hline Psiges sajos & 70 & 28 \\
\hline Wontega & PS & 2 \\
\hline Augtria & 80 & 18: \\
\hline Polania & 19 & 79 \\
\hline Ponugai & 43 & 44 \\
\hline Buevia & 97 & 2 \\
\hline Sura & 71 & 20. \\
\hline Egparda & $4 \pi$ & 51 \\
\hline
\end{tabular}

Fuente: Camara Alemana

En el gráfico n. ${ }^{\circ} 4$ se muestran los tipos de consumo de café en Alemania, el de café con leche es mayor (67\%) al de café negro (33\%). Se advierte un consumo per cápita de cuatro tazas diarias. Estudios clínicos demuestran que cuatro tazas al día no causan daño alguno a la salud humana (desayuno, media mañana, después del almuerzo y en la tarde). 


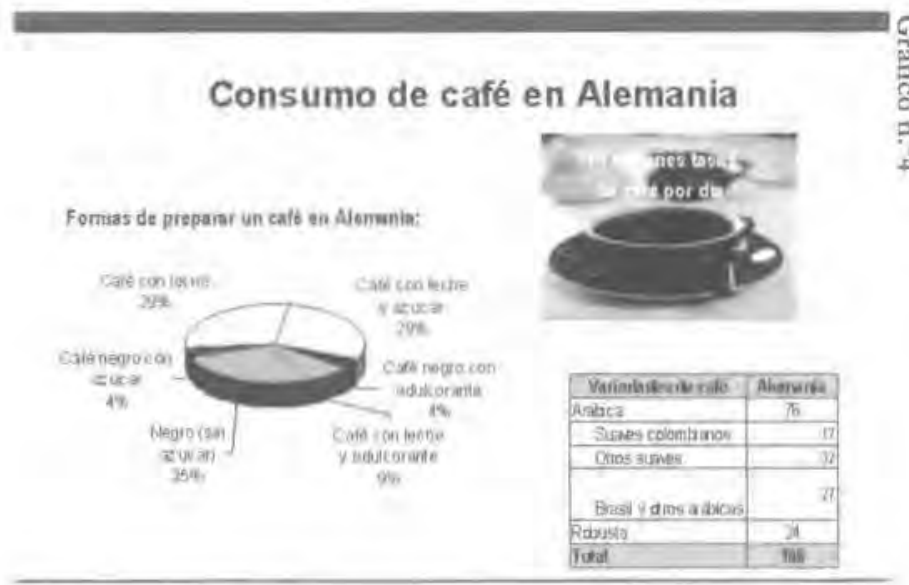

En el escenario internacional, existe una creciente preocupación por la crisis del café (caída del valor de las exportaciones, exceso de producción, aumento permanente de la oferta, baja calidad y perjuicio para productores). Estados Unidos evalúa su retorno a la Organización Internacional del Café con el propósito de concertar estrategias que eviten mayores daños a las economias de los pequeños productores cafetaleros del África, América Latina y Asia. Las propias transnacionales, como Nestlé, Philip Morris, Procter \& Gamble (tostadurias), proponen la búsqueda de soluciones estructurales vinculadas a la sobreoferta mundial de café. Adicionalmente, existe una creciente presión política de los consumidores, que reclaman la adopción de códigos de conducta por parte de las grandes tostadurías de café para superar la enorme brecha de precios que afecta, principalmente, a los productores. La Federación Europea del Café, a propuesta de Nestlé y Kraft Foods, está avanzando en la definición de parámetros que serían incorporados en códigos para la 
producción de café ambientalmente sostenible, los casos de sostenibilidad de las organizaciones de productores, y la calidad del producto.

\section{Elcafé en el Perú}

El 2003 no ha sido un buen año para el café; se estima que la cosecha fue inferior en un $25 \%$ (aproximadamente un millón de quintales menos) a la del 2002, en el que se cosecharon 3 millones 836 mil quintales, esto tendrá un impacto negativo importante en la economía de los pequeños productores.

En la actualidad, el café se ha constituido en el producto agrícola que genera más divisas, con excepción del año 2003, cuando fue superado por el espárrago. En el año 2000, las exportaciones de café fueron de 143 mil toneladas, lo que significó un ingreso en divisas de 223 millones de dólares, es decir, el $90 \%$ de las agroexportaciones tradicionales.

La producción está concentrada en cuatro departamentos, que, conjuntamente, representan el $73 \%$ del total: Junin (24\%), Cajarnarca (21\%), Cusco $(15 \%)$ y San Martín (13\%). En el mediano plazo se espera recuperar cien mil hectáreas para el cultivo del café como consecuencia de las políticas de erradicación y sustitución del cultivo de coca. El rendimiento promedio del cultivo es de 0,67 toneladas por hectárea.

El consumo per cápita sería de 0,6 kilos al año, uno de los más bajos en Latinoamérica; mientras que en Ecuador, Bolivia y Colombia es de 3,$8 ; 2,4$ y 2,2 kilos al año, respectivamente. Los productores destinan al mercado doméstico el café de menor calidad.

La oferta del producto procede de pequeños agricultores, cuya producción es exportada por grandes traden internacionales. La principal empresa exportadora es Perales Huancaruna (Perhusa), con una participación de 29,1\%. 
En la producción de café, Perú no goza de ventanas de oportunidades (contraestación), como sí lo hace con productos como el espárrago, dado que en el Hemisferio Sur se encuentran los principales productores mundiales de café: Brasil y Colombia.

El gráficon. ${ }^{a} 5$ nos permite apreciar las producciones por departamento, entre las que se advierte las contribuciones significativas de Cusco, San Martín y Junín. Por otro lado, el gráfico n. ${ }^{0} 6$ muestra que la superficie cosechada, el volumen de producción y el rendimiento por hectárea se incrementaron significativamente en el periodo 1990-2002.

\begin{tabular}{|c|c|c|c|}
\hline \multicolumn{4}{|c|}{ PROOUCCION OE CAFE (99) } \\
\hline \multicolumn{4}{|c|}{ Reriodo: Enero-Abril Pi } \\
\hline Depsrtamantes & 2002 & 2003 & var. to \\
\hline Nacional & $764,416.3$ & $755,977.6$ & $-1.1 \%$ \\
\hline Arnazonas: & $60,201.1$ & $42,127.6$ & $-30.0 \%$ \\
\hline Ayacucho & $11,521.7$ & $41,347.8$ & $258.9 \%$ \\
\hline Cajamarca & $48,455.9$ & $46,172.8$ & $-4.7 \%$ \\
\hline Cusco & $195,842.0$ & $189,347.8$ & $-3.3 \%$ \\
\hline Huancavelica & 152.2 & 108.7 & $-28.6 \%$ \\
\hline Huanuco & $11,934.8$ & $14,239.1$ & $19.3 \%$ \\
\hline Junin & $209,239.1$ & 199,1304 & $-48 \%$ \\
\hline La Libertad & 1.884 .8 & 1.9250 & $2.1 \%$ \\
\hline Madre de Dios. & 619.6 & 404.3 & $-34.7 \%$ \\
\hline Pasco & $10,543,5$ & 18.195 .7 & $72.6 \%$ \\
\hline Piura & 5870 & 21,7 & $-96.3 \%$ \\
\hline Puno & $39,369.6$ & $36,739.1$ & $-67 \%$ \\
\hline San Martin & $169,880.0$ & $165,369.6$ & $-27 \%$ \\
\hline Ucayall & 4,1852 & 847.8 & $-79.7 \%$ \\
\hline
\end{tabular}

Fuente: Direcciones Reglonales y Subregionales de Agricultura Elaboración AgroData-CEPES. 


\begin{tabular}{|l|l|l|l|}
\hline \multicolumn{4}{|c|}{ CAFE - Superficie cosechada, producción y } \\
rendimiento $1990-2001$
\end{tabular}

Dado el alto volumen exportable de café, su cotización, incluso en chacra, ha sufrido progresivamente el deterioro vía sobreoferta mundial y reducción de precios en el mercado internacional, esto se puede apreciar en el gráfico n. ${ }^{\circ} 7$. 


\begin{tabular}{|c|c|c|c|c|}
\hline \multicolumn{5}{|c|}{ Precios en chacra del cafe (Soles $\mathrm{x}$ quintales) } \\
\hline Mes 1 Año & 2000 & 2001 & 2002 & 2003 \\
\hline Enero & 156.1 & 118.3 & 84.2 & 93.2 \\
\hline Febrero & 167.4 & 94.5 & 90.2 & 91.5 \\
\hline Marzo & 166.0 & 90.4 & 85.4 & 84.5 \\
\hline Abril & 162.3 & 93.1 & 94.2 & 96.1 \\
\hline Mayo & 162.1 & 121.8 & 87.9 & \\
\hline Jun is & 154.6 & 109.9 & 81.8 & \\
\hline Julio & 146.0 & 101.9 & 87.1 & \\
\hline Agosto & 136.9 & 95.9 & 87.0 & \\
\hline Septiembre & 138.8 & 92.6 & 100.0 & \\
\hline octubre & 139.7 & 79.6 & 103.5 & \\
\hline Noviembre & 136.1 & 82.6 & 92,7 & \\
\hline Diciembre & 128.1 & 80.2 & 91.4 & \\
\hline
\end{tabular}

Fuente: Minag-Dgia

En el gráfico $n,{ }^{\circ} 8$ se observa que Pethusa (Perales Huancaruna) ya marcaba un significativo liderazgo en la exportación de café en el primer semestre del 2003 y orientaba sus volúmenes de exportación, principalmente, a Alemania y Estados Unidos.

\begin{tabular}{|c|c|c|c|}
\hline EXPORTACIONES DE CAFE POR EMF & SAS: Valor FC & $08-\mathrm{E}$ & SUNO - 2003 \\
\hline & VALQR FOB & PESO NETO & PRECIOFOB \\
\hline EMPRESA & (Uss) & $00-49 \mathrm{~kg}$ & PROMEDIO \\
\hline & & & (Uss) \\
\hline 1 PERALES HUANCARIUNA & $12,043,701.86$ & 239.600 .39 & 5027 \\
\hline 2 LOUIS DREYFUS & $6,342,71782$ & 141209.61 & 44.92 \\
\hline 3 CIA INTERNACIONAL DEL CAFE & $3,129,01119$ & 57,15154 & 54,71 \\
\hline 4 YALDIVIA CANAL HUGO & $3,028710,02$ & 77,36152 & 39.13 \\
\hline 5 PROCESADORADEL SUR & $2,831,603,37$ & 51,60448 & 54.87 \\
\hline E MACHUPICCHU COFFEE TRADING & $2,350.141 .72$ & 63,16207 & 3721 \\
\hline 7 CENTRAL COCLA & 2,33481227 & $32,956,91$ & 72.15 \\
\hline
\end{tabular}




\begin{tabular}{|c|c|c|c|}
\hline 8 CAFETALFRA AMAZONICA & $1,765,06622$ & 31,98511 & 5518 \\
\hline 9 COMERCIO \& CIA & 1.679 .41093 & $36,890,98$ & 45.52 \\
\hline 10ANTONIO RINALDI & $1,401,627,34$ & 25,80471 & 5432 \\
\hline 11 ROMERO TRADING & 1.31191171 & $25,069.24$ & 52.33 \\
\hline 12 AGROINDUSTRIAL ARRIOLA & $1,202,35396$ & $23,535,33$ & 5109 \\
\hline 13 LAUMAYER PERU & $1,028,26495$ & $17,122,24$ & 60.03 \\
\hline 14 CAC LA FLORIDA & 880,43437 & $10,786,50$ & 8162 \\
\hline 15 ASOC R DE MENDOZA. & 654,91402 & 4,87500 & 134.34 \\
\hline 16 COEX PERU & 644,820 of & $11,100.00$ & 58.09 \\
\hline 17PERCOF & 565,96180 & $12,748.26$ & 44.49 \\
\hline 19PRONATUR: & $533,215,0 \mathrm{~g}$ & 7.930 .50 & 67.24 \\
\hline 19 CECOVASA & $434,022.68$ & 5,03750 & 71 \\
\hline 20|TRADE PROIECT \& INVESTMENT & $412,5652 \mathrm{~d}$ & $10,999,72$ & 3751 \\
\hline
\end{tabular}

Fuente PROMPEX - ADUANAS Elaboración: junta Nacional del Café - JNC.

El gráfico n. ${ }^{\circ} 9$ muestra las participaciones de los distintos paísés importadores del café peruano. Se puede apreciar que, análogamente a sus participaciones en el gran mercado global, Estados Unidos y Alemania son nuestros principales demandantes. Recientemente, viene incrementándose la demanda y cotización por variedades orgánicamente cultivadas.

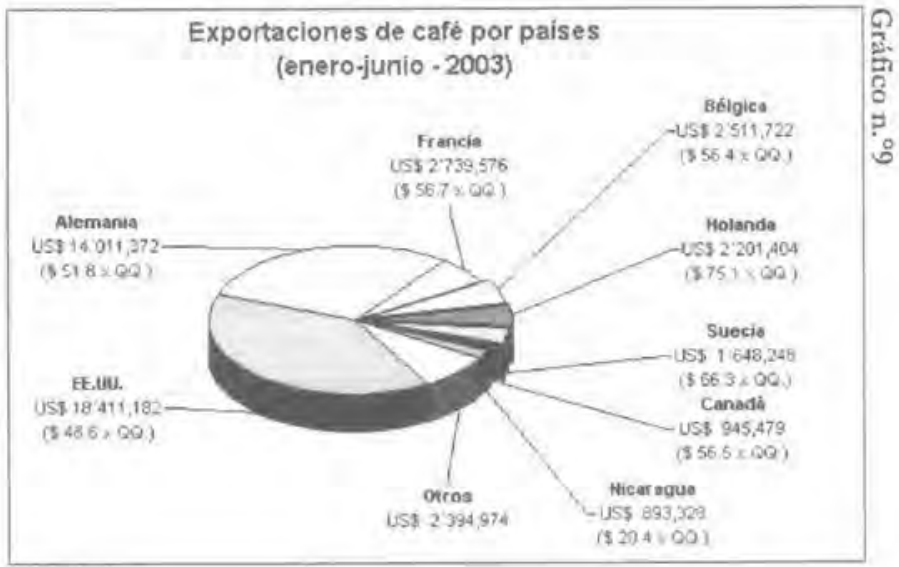

Fuente Frompes 


\section{Perhusa-Café Altomayo}

Nuestra Amazonia ha cobijado a familias que pertenecen a los grupos más pobres y vulnerables del pais. El incremento del desempleo, la informalidad laboral, la ausencia de servicios públicos y del estado agudizan este panorama; sin embargo, siempre existirán oportunidades y hombres protagonistas dispuestos a cambiar la realidad. Este es el caso del café y de la familia Huancaruna-Perales, Ubicados en la zona de Altomayo, desarrollan su actividad cafetalem no solo mediante sembríos propios, sino incorporando campesinos a los que irán capacitando progresivamente hasta convertirlos en hábiles cultivadores de una de las variedades de café aromático más preciada en los mercados de calidad.

Las excelentes condiciones climáticas de la zona de ceja de selva (zonas altas) son aprovechadas para el desarrollo de las variedades arábigas de café, así como la posibilidad de sembrar cafetos bajo sombra (café atomático). Las siembras son poco tecnificadas, sin embargo, esta limitación es transformada en una fortaleza. Al realizarse mejoras de procesos a los cultivos manuales, no se utilizan pesticidas ni herbicidas, con lo que se logra cosechas «orgánicas» y se mejora las productividades con la asistencia técnica de ingenieros de Perhusa. La familia se vuelve una unidad económica: al intervenir todos en las actividades agrícolas, pueden elevar sus magros ingresos familiares; increíblemente, la actividad económica se vuelve una actividad que integra a la familia, les incorpora valores y mejora su bienestar.

Pese a la crisis internacional del sector cafetalero, Perhusa ha ido incrementando, año a año, sus volúmenes exportables, así ha logrado un posicionamiento en los principales países desarrollados con un producto de altísima calidad. Han tomado nota de que las variedades cultivadas 
orgánicamente son percibidas y diferenciadas por los consumidores sofisticados. Actualmente, sus demandas y cotizaciones están creciendo de manera significativa.

El bajo consumo per cápita nacional animó a que el grupo lanzara Café Altomayo como una marca para el mercado local, inicialmente. Sus esfuerzos por manteneruna excelente calidad yuna apropiada estrategia comercial han permitido que hoy en día posea la cuarta parte de la participación del mercado.

Todas sus iniciativas buscan mantenerse en armonía con la naturaleza, generando un manejo sostenido del campo, respeto por la ecología (no contaminar) ymejorando las condiciones de vida de los campesinos de la zona.

\section{Misión}

"Queremos ser líderes de clase mundial en alimentos, cuestionaremos permanentemente las formas convencionales de competir y actuaremos siempre en armonia con la naturalezay, esta es la misión del Grupo Perhusa, corporación que controla a Altomayo Perú, empresa productora de café Altomayo. Perhusa lleva cuarenta años en el negocio cafetalero y veinticinco en exportaciones a Norteamérica, Asia y Europa; en la actualidad, es la empresa líder en exportación de café.

En todo el país y a lo largo de la cadena productiva cafetalera, Perhusa contribuye con la comunidad generando empleo y sustento a más de cuarenta mil familias, entre agricultores, acopiadores, comerciantes, transportistas y otros proveedores de servicios; además de profesionales y técnicos competentes que con su esfuerzo y compromiso han lograda que cada vez más personas prueben y prefieran el sabor natural del café. 
Para producir este sabor que deleita el paladar de muchos y que permite pasar agradables momentos, cada mañana en los cafetales de los valles y montañas de la amazonía peruana, los caficultores de la zona son apoyados por los ingenieros agrónomos de Perhusa para cuidar cada detalle del cultivo y cosecha del café. De la misma forma, en el proceso de elaboración tambiẻn se asegura la calidad y pureza de este fruto que llega de los cafetales a las tazas del público consumidor.

Impresionan sus cifras: cincuenta millones de dólares anuales en exportaciones y cuarenta mil familias empleadas a lo largo de la cadena cafetalera, además de haber realizado inversiones en otros sectores relacionados, tales como transporte y agroexportación.

Ricardo Huancaruna (bijo), principal ejecutivo de Perhusa-Altomayo, educado en Alemania, observa que los alemanes aprecian las variedades aromáticas de café, se involucra en los procesos de tostado y aprende a identificar los puntos críticos en la producción de café. A su retorno al Perí, toma nota de que las variedades aromáticas crecen bajo sombra y que, luego de las grandes talas de los principales bosques europeos y norteamericanos, quedan pocas zonas en el mundo para cultivar estas variedades. Se concentra, entonces, en desarrollar el negocio familiar cafetalero iniciado por su padre, pero afianzándolo con las mejores prácticas aprendidas en Europa. Su prioridad es la exportación, cree que deben ser más competitivos, para ello, tienen que ser mejores.

\section{Estrategias}

- Mejoramiento de prácticas en el campo (capacitación) y en las labores culturales, asi como de los niveles de vida de los trabajadores 
- Se genera valor social: Perú es sinónimo de los Andes

- Buena estrategia de marketing: les permite apoderarse de la cuarta parte del mercado peruano de café soluble

- Han sabido por dónde ir desde el principio

- Amor al trabajo

- Innovación buscando nuevas formas de competir

- Se han dedicado a hacer lo mejor que saben hacer: Café

- Pensamiento de largo plazo

- Mano de obra competitiva en todos los niveles

- Trabajo en equipo

\section{Qué se quiere}

- El café como el mayor ingreso de divisas agropecuarias

- Presencia de Altomayo en los mercados del mundo

\section{Lecciones aprendidas}

- Nunca dejaremos de aprender

- No hay que distraerse, hay que enfocarse

- Si no se conoce un mercado, mejor no ingresar

- Humildad para potenciar las capacidades de todos los que compartimos la visión y misión de este grupo empresarial

- Así como el fracaso es responsabilidad de muchos, el éxito es mérito de todos 


\section{Elementos críticos}

- Cambia de manera permanente sus formas de competir

- Está en armonia con la naturaleza

- Siempre está presente el factor humano

- Han entrado a lugares donde el gobiemo no está

- El éxito dependía de sus propias fuerzas, de sus variables controlables

- Tiene similitudes con la gestión empresarial japonesa: identidad nacional; la familia como corazón de la sociedad

- Tiene un compromiso con el trabajo

- Está con la gente, con los trabajadores

- Existe trabajo en equipo

- El desarrollo del grupo ha sido más evolucionista, se avanza y se consolida

- Se han diversificadoen actividades concéntricas a su experticia clave: bacer café

- Asume actividades emblemáticas: exportaciones, agticultura, empleo

- Posee ventaja competitiva en productos otgánicos, nicho de mercado

- La cosecha es a mano

- Vende una buena bebida, solidaridad con el subdesarrollo, y la ecología

- Productos con mayor valor agregado: café + energizantes

- No hacer nada si usted no ha descubierto su cuello de botella, su restricción.

- Tiene que ser sincero, tanto en sus políticas como en lo que nosotras creemos que es lo que quiere el cliente

\section{Conclusión}

En el corto y mediano plazo, el país requiere de iniciativas como las de Perhusa-Altomayo, quienes, desarrollando una iniciativa empresarial, reconocen 
lo central de la familia como factor de crecimiento económico, y el valor de formular propuestas sostenibles y en armonia con la naturaleza.

Actualmente, existen dos frentes comerciales que están desarrollando el mercado internacional, donde cada vez ganan mayor participación, y el mercado local a través de la marca Altomayo, con cuyos factores críticos de calidad y sabor piensan incrementar aún más su participación de mercado.

Toca, entonces, observar que otras cadenas cafetaleras pudieran replicar de manera parcial o completa las estrategias de Perhusa-Altomayo y ser exitosas, que otras cadenas productivas agroexportadoras pudieran ser estimuladas o impulsadas para generar mayor crecimiento y bienestar. Tenemos espárragos, cítricos, paltos, mangos, uva de mesa, algodón, entre muchas variedades que deberían ser materia de análisis y de formulación depropuestas.

Realmente, el Perú es un país rico en variedades, pero pobre en estrategias, crearlas es el reto de las nuevas generaciones. Entender nuestra realidad, analizarla, procesar hipótesis, imaginar actividades y generar el cambio: esa es nuestra tarea actual en la Universidad Católica Sedes Sapientiae. 